\title{
The Effectiveness of Microlearning to Improve Students' Learning Ability
}

\author{
Gona Sirwan Mohammed ${ }^{1}$, Karzan Wakil ${ }^{2,3}$, Sarkhell Sirwan Nawroly ${ }^{4}$
}

\begin{tabular}{l} 
ARTICLE INFO \\
\hline Article History: \\
Received 15.02.2018 \\
Received in revised form \\
16.04 .2018 \\
Accepted \\
Available online 01.07 .2018
\end{tabular}

\section{INTRODUCTION}

The rapid changes in our world constantly affect our private life and working environment. The need for quick learning becomes an important factor for improving everyone's life (Gassler, Hug, \& Glahn, 2004). Traditional learning is unable to lead students towards innovation and creativity because traditional learning cannot motivate students to learn new things. Moreover, the knowledge which students are gaining from traditional teaching method is easily forgotten (Hug \& Friesen, 2007). It has been reported that traditional learning process can reduce the student's attention as the US National Center for Biotechnology Information mentioned that the average of the attention span of students decreased from 12 to 8 seconds between 2000 and 2013 when traditional method as adapted (Renard, 2017).

Microlearning is a new teaching method with no specific definition yet, strictly related to e-Learning. Microlearning puts knowledge in small and understandable fractions. Nowadays, almost everyone who taps into internet gets benefits from Microlearning meaning Googling, checking email, reading and watching web contents on the Internet. Interestingly, the smart mobile devices enable us to tap into the latest release of information as well. Microlearning grants learners to access the newest information whenever, wherever, and in the format that they require. Additionally, due to the available features, in Microlearning method the learning speed is chosen by students themselves. They can access the studied content as much time as they like at the pace that they desire. Therefore, Microlearning methods can provide the students with the required knowledge and skills they need as they discover a path in their individual life (Gutierrez, 2015). Though most of the efforts in Microlearning is about learning languages (Cates, Barron, \& Ruddiman, 2017), we believe that Microlearning methods should extend to other fields of learning as well.

With the world's constant demand and complexity, increasing learning efficiency is crucial. Therefore, implementing Microlearning process in different school categories such as Primary schools and high schools within various locations, it is an important and challenging step in the educational process (Choosing different school categories will serve as a tool to find the effects of Microlearning on students in different ages and choosing different locations will show the impact of social life, culture, and tradition on the education system. In this paper, we tested Microlearning methods in Primary school at Sulaimani city. We try to find the effect of Microlearning in ICT Subject and how it will motivate students.

\footnotetext{
${ }^{2}$ Corresponding e-mail: karzanwakil@gmail.com , orcid.org/0000-0003-1838- 4906, Institute of Training and Educational Development in Sulaimani-Iraq ${ }^{1}$,orcid.org/0000-0001-9414-7975, University of Human Development-Iraq ${ }^{2}$, Sulaimani Polytechnic University-Iraq ${ }^{3}$, Komar University of Science and Technology-Iraq , orcid.org/0000-0003-3290-9975
} 
Mohammed,G.S., Wakil,K. \& Nawroly,S.S. (2018). The effectiveness of microlearning to improve students' learning ability. International Journal of Educational Research Review,3(3),32-38.

The paper is organized as follows: Section 2 discusses the previous research attempts in the area of Microlearning. Section 3 displays the prepared research process for solving the problem. section 4 presents the result of research process implementation. Finally, section 5 presents some concluding remarks and points for future works.

\section{RELATED WORK}

There are several researches conducted in the area of Microlearning. The authors in (Freeman, 2016) used Microlearning-friendly materials in the format of video contents. They used these videos to introduce Microlearning to others in term of term, explanation, examples, potential and Microlearning experience demands. While in (Ozdaml, Kocakoyun, Sahin, \& Akdag, 2016), the researchers tried to show the opinion of students for the infographics as a Microlearning tool which are shown to them in anatomy class. The qualitative research method that they used for their research model was case study. The students who participated were registered for anatomy course. They were from Near East University, Physical Education and Sports Departments. The numbers of participants were 140 students and the duration of the educational period was six weeks. Before performing the study, students were given awareness about infographics. Then, under the curriculum of anatomy, the infographics of digestive system's anatomy were showed to the students. After the presentation, a form was given to the students for a semi-structured interview to get their opinions about infographics anatomy in the course. The feedback showed that more than half of the students didn't know what is "infographics" and what does it mean, they also, more than that stated that they never saw infographics in classes. However, after the six weeks of teaching using Flashcards as a Microlearning tool, the students stated that they had a better experience with infographics than traditional methods and visuals. They stated the infographics as satisfying and easy to understand. On top of that, the study showed that utilizing infographics is not just effective it also can stay memorable for longer periods. Thus, it is important to convert traditional courses into easy-to-understand ones by using infographics.

However, in (Baumgartner, 2013), the paper shows an educational classification as a framework for educational interactions and planning. The proposed work develops a table with two dimensions, one of the dimensions involves different stages of didactical attributes and the other covers educational actions variations. The research illustrates educational motivations, reasons for this classification and its functionality. The second part of the paper shows the suitability of Microlearning in the common taxonomy framework. It tries to deal with actual differences to other educational areas in the classification and finding the reason behind the necessity of various theoretical approaches for the classification area. The authors suggested adapting theory of communicative action which is developed by Jürgen Habermas in his work to further improvement in Microlearning method.

The method which is proposed in (Edge, Fitchett, Whitney, \& Landay, 2012) is called MemReflex. It is used to get fast-feedback from learners. They used Flashcard systems to help students to learn facts about definitions, names, and dates. It depends on robust memorizations with posterior tests which come up to days later after using the Flashcards. This approach does not only utilize the short, scattered, dynamic opportunities for Microlearning throughout the day but also doesn't help learners who want motivation which is sourced from infallible study sessions. By retesting new objects in rapid sequence, and dynamicalscheduling future tests based on the type of students' memory, the MemReflex system that they proposed by using flashcards had given fast-feedback. The evaluation of MemReflex carried out through three user studies. The first two studies showed the effectiveness of audio with text form. They should provide good results even when the learner is walking and distracted. The third study was about vocabulary learning in second-language. They showed how MemReflex could improve the confidence, accuracy, perception of control and success. Also, they point out a new way for mobile, Microlearning and Micro activities.

In previous works, we found the effective technology in teaching and learning in the Primary and high schools. In the ones we present how enriching classroom by using new technology (Wakil, Qaisar, \& Mohammed, 2017), in another one we found the side effect of electronic games on the students GPA (Wakil, Omer, \& Omer, 2017), also we explained how ICT subject has a positive role in the Primary schools (Wakil, Muhamad, Sardar, \& Jalal, 2017). After this section, we will go to finding effective Microlearning in the process learning. 
Mohammed,G.S., Wakil,K. \& Nawroly,S.S. (2018). The effectiveness of microlearning to improve students' learning ability. International Journal of Educational Research Review,3(3),32-38.

\section{METHODOLOGY}

In this section, we will introduce the methodology of our work. We separated two groups of seventh grade in a school and test Microlearning methods in one of them and traditional learning in the other. The students participated in each group is equal numerically with approximately at the same academic level. We taught five subjects for six weeks using both traditional learning and Microlearning. Then we tested the students and compared the outcomes of their feedback. Our working process follows the steps which are shown in Figure 1.

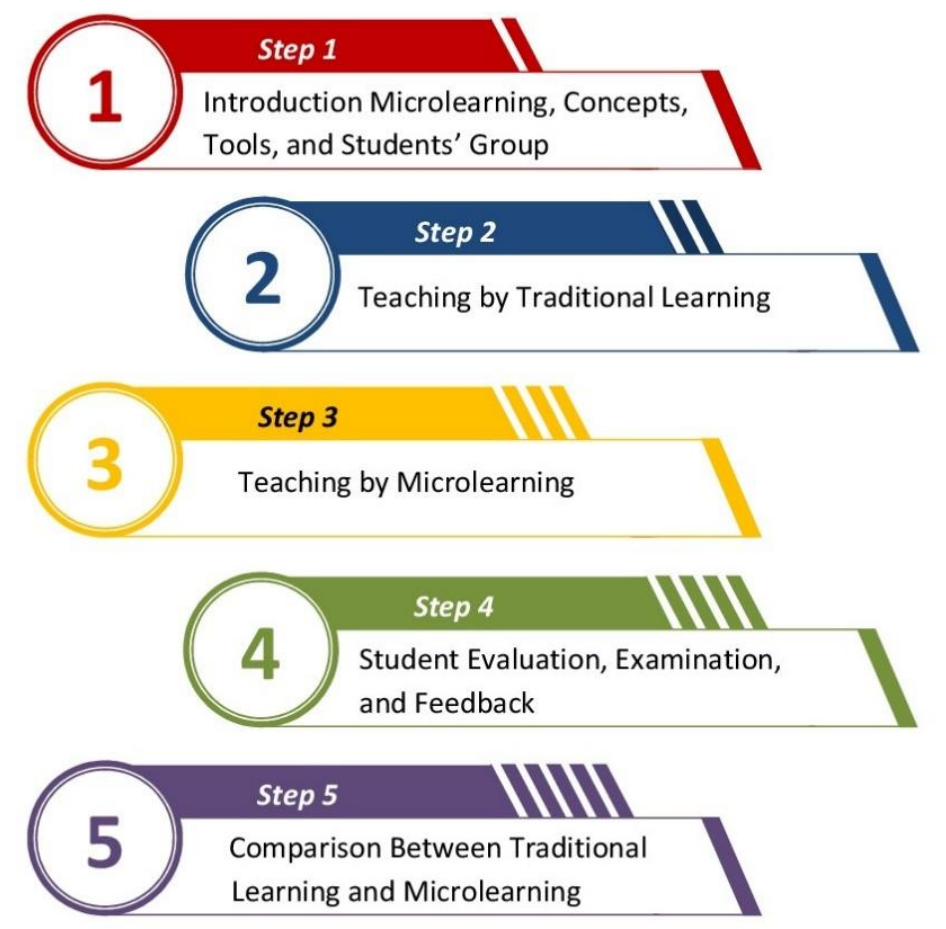

Figure 1. The Process of Solving the Problem

Our working flow is going through five steps. In the first step, we introduce the basics and tools used to introduced Microlearning to our first group of students. The introduction mechanism started by telling stories, followed by a discuss session related to the subject. During some sessions, the stories were accompanied by a played video to deliver a large amount of knowledge in a short period. We also used flashcards printed or shown using a data projector, afterward a question session was performed on the flashcards or the students were asked to perform a certain task.

We also used posters and infographics to clarify a topic to the students. Then, we asked them to do a play or activity during the class. Finally, A test was performed with taking feedback from the students during class time. This mechanism was applied for introducing Microlearning method for this group entirely.

The second step in our process is teaching a class using traditional learning system. According to this method, the teacher will be the center of the class and lesson teaching process will be only performed by using the books only. We selected five subjects; four of them are from their main subjects provided by their curriculum. However, the fifth subject is called "Safety and Health at computer usage" was an extra subject not included in the student's curriculum. Then we will test the students, and the outcomes will be collected. The third step is teaching the class by applying Microlearning method. As the second step, five subjects are selected. Then, the students tested, and the outcomes will be collected. Several tools are required to perform this method such as: computers, internet connection, laser presenter, whiteboard, short videos, and colored papers for making posters for the subjects related to the student's curriculum.

The fourth step is evaluating the students by asking a question, displaying pictures and asking about it, or organizing and ordering some mixed pictures based on instructions given to them. Then, examining the 
Mohammed,G.S., Wakil,K. \& Nawroly,S.S. (2018). The effectiveness of microlearning to improve students' learning ability. International Journal of Educational Research Review,3(3),32-38.

students will be carrying out individually in the all five classes in different days without prior notification. The results will be collected, graded for both traditional group and Microlearning group. Finally, a feedback form will be provided to the students in Microlearning group to evaluate the extent of interest that they had toward Microlearning methods in the class. The fifth and final step is comparing the outcomes of Microlearning with traditional learning.

\section{RESULT AND DISCUSSION}

In this section, we will apply the mentioned methodology in the previous section. We have two groups of twenty-two students for each. Each group is at the same age and approximately at the same academic levels. As mentioned before, we taught five subjects in ICT lessons in five weeks. Then, the sixth week was dedicated to evaluating, testing, and taking feedbacks. The subjects are "Safety and Health at computer usage" (it is not in their curriculum), which teaches the student how to use computers. The second subject is Computer and computer parts. The third subject is about Computer main memory. Then, the fourth one is about computer discs and storage devices. The final subject is about how to operate and shut down computers.

Generally, in traditional learning, the teacher is the center of the learning process and the students are mostly passive learners. Therefore, the teacher only taught what is inside the book and students inquired to listen to the lessons and pay attention with almost negligible participation in the class. Nonetheless, in Microlearning method, everyone is center of the learning process in the class. The students can use many different methods and teaching tools during the class session such as: giving stories related to the subject, tutorial videos, school books, flashcards, posters, playing and activities. Finally, evaluating the students will be conducted during the class time (for more details, refer to section 3 ).

Upon the sixth week, we performed exams for all taught lessons in both groups, five for the traditional group and five for Microlearning group without prior notification. The results of the exams and their grading were collected, as illustrated in Table 1, traditional learning group showed $64 \%$ passing rate, while, Microlearning group's rate $82 \%$.

Table 1. Evaluating the rate of the pass between traditional learning and Microlearning

\begin{tabular}{|c|c|c|c|c|c|c|c|}
\hline \multirow{2}{*}{ Learning Method } & \multicolumn{5}{|c|}{ Subjects } & \multirow{2}{*}{$\begin{array}{l}\text { Passing } \\
\text { average }\end{array}$} & \multirow{2}{*}{$\begin{array}{l}\text { Difference } \\
\text { average }\end{array}$} \\
\hline & First & Second & Third & Fourth & Fifth & & \\
\hline Traditional & $65 \%$ & $66 \%$ & $59 \%$ & $65 \%$ & $67 \%$ & $64 \%$ & \multirow{3}{*}{$18 \%$} \\
\hline Microlearning & $84 \%$ & $84 \%$ & $77 \%$ & $83 \%$ & 84 & $\% 84$ & \\
\hline Difference & $19 \%$ & $18 \%$ & $18 \%$ & $18 \%$ & $18 \%$ & $18 \%$ & \\
\hline
\end{tabular}

We gave the students in Microlearning group a feedback form to evaluate their motivation for learning based on using Microlearning tools. Their responses are shown in Table 2.

Table 2. Student's feedback for Microlearning tools

\begin{tabular}{ll}
\hline Microlearning tools & Percentage \\
\hline Playing and activities & $97 \%$ \\
\hline Short tutorial videos & $95 \%$ \\
\hline Flashcards & $94 \%$ \\
\hline Posters and infographics & $94 \%$ \\
\hline Telling stories & $92 \%$ \\
\hline
\end{tabular}

As we can notice, from the first class the difference in passing rate is $19 \%$ which is the highest record. It occurred because Microlearning method as introduced to the students for the first time and they had a positive reaction towards the new teaching method. As in the rest of the lessons, the students became more and more adaptive to Microlearning methods. Therefore, their learning results showed $18 \%$ better rate than traditional learning. We set the passing scale for the exams that the students performed, as shown in Table 3 . 
Mohammed,G.S., Wakil,K. \& Nawroly,S.S. (2018). The effectiveness of microlearning to improve students' learning ability. International Journal of Educational Research Review,3(3),32-38.

Table 3. the passing scale and their corresponding grades

\begin{tabular}{ll}
\hline Scale & Grade \\
\hline Fail & $0-49$ \\
\hline Good & $50-69$ \\
\hline Very good & $70-89$ \\
\hline Excellent & $90-100$ \\
\hline
\end{tabular}

In Table 4, we illustrated the ratio of passing in traditional learning and Microlearning. The results for passing and failing students are measured.

Table 4. Failing number and rate for traditional learning and Microlearning groups

\begin{tabular}{llllll}
\hline \multirow{2}{*}{ Lessons } & $\begin{array}{l}\text { Student numbers per } \\
\text { group }\end{array}$ & \multicolumn{2}{l}{ Traditional learning students } & \multicolumn{2}{l}{ Microlearning students } \\
\cline { 2 - 6 } & 22 & Failed number & Failed rate & Failed number & Failed rate \\
\hline 1 & 22 & 6 & $23 \%$ & 0 & $0 \%$ \\
\hline 2 & 22 & 8 & $27 \%$ & 0 & $0 \%$ \\
\hline 3 & 22 & 6 & $36 \%$ & 0 & $0 \%$ \\
\hline 4 & 22 & 6 & $27 \%$ & 0 & $0 \%$ \\
\hline 5 & & $27 \%$ & 0 & $0 \%$ \\
\hline
\end{tabular}

Figure 2 shows a chart which two different-colored columns. The blue column shows Microlearning, and the red one indicates traditional learning results.

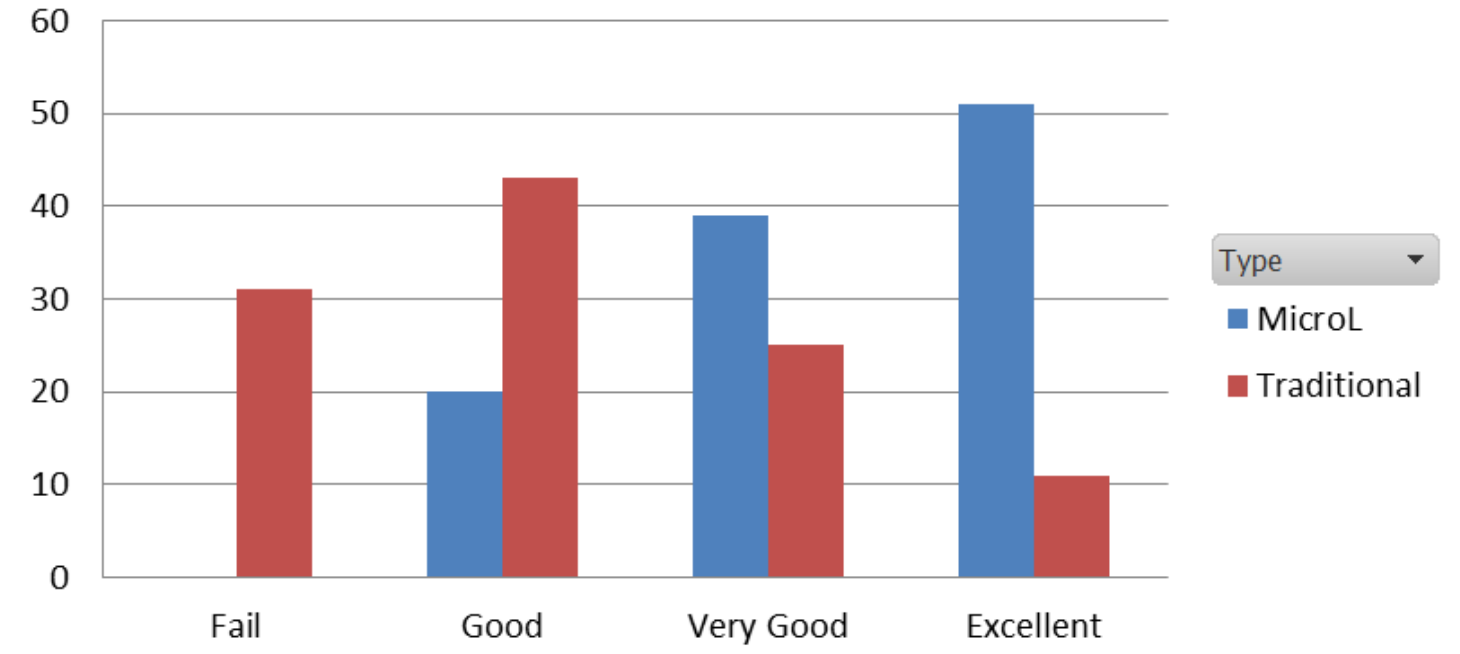

Figure 2. Difference in failing students in traditional learning and Microlearning

As illustrated, Microlearning groups had no failing students compared to traditional learning. Also, the excellent grades are highest among other grades for Microlearning. On the other hands, traditional learning's highest grade is "Good." These results show that Microlearning methods can help students to maintain the knowledge in their memories for longer periods. Table 5 shows the ratio of students' grades for each scale in both learning systems.

Table 5. Comparison for scale grades ratio for students

\begin{tabular}{lll}
\hline Grade & Traditional learning & Microlearning \\
\hline Fail & 31 & - \\
\hline Good & 43 & 20 \\
\hline Very good & 25 & 39 \\
\hline Excellent & 11 & 51 \\
\hline Total & 110 & 110 \\
\hline
\end{tabular}


Mohammed,G.S., Wakil,K. \& Nawroly,S.S. (2018). The effectiveness of microlearning to improve students' learning ability. International Journal of Educational Research Review,3(3),32-38.

Table 6 shows our questionnaire form which we gave to the students, asking them to fill it accordingly. At the beginning of the questionnaire, we mentioned the reason behind this study. We mentioned that "This study is to deliver Microlearning methods to other educational institutes and schools. Please answer questions correctly; your answers are our concerns". At the end of the questionnaire, we said: "If you have any opinions, please write it."

Table 6. Feedback form in the format of the questionnaire

\begin{tabular}{|c|c|c|c|c|c|c|}
\hline No. & Questions & $\begin{array}{l}\text { Strongly } \\
\text { disagree }\end{array}$ & Disagree & Normal & Agree & $\begin{array}{l}\text { Strongly } \\
\text { agree }\end{array}$ \\
\hline 1 & $\begin{array}{l}\text { What do you think about telling stories related } \\
\text { to the lesson's subject? Do you like to embed } \\
\text { stories into your lessons? }\end{array}$ & & & & & \\
\hline 2 & $\begin{array}{l}\text { Do you like the teacher to show you videos } \\
\text { related to your subject? }\end{array}$ & & & & & \\
\hline 3 & Do you like to use Flashcards in the class? & & & & & \\
\hline 4 & $\begin{array}{l}\text { What do you think about using posters and } \\
\text { infographics? }\end{array}$ & & & & & \\
\hline 5 & $\begin{array}{l}\text { Do you like to play or have activities related to } \\
\text { the lesson? }\end{array}$ & & & & & \\
\hline
\end{tabular}

After we gathered the student's answers from the survey, we analyzed the data and put the results in a pyramid graph as shown in Figure 3.

Playing

and

Activities $97 \%$

Watching Videos $95 \%$

Flashcards 94\%

Posters and Infographics 94\%

\section{Telling stories $92 \%$}

As the figure indicates, student's desire for playing and carrying out activities during the lesson is at maximum which is $97 \%$. While telling stories takes the minimum which is $92 \%$.

\section{CONCLUSION AND FUTURE WORK}

Throughout this study, we collected the data from exams, feedback forms, and questionnaire for both traditional learning and Microlearning. Then, we analyzed the data, and drew the results for both teaching methods. Based on the results, we came up with the conclusion that using Microlearning method can improve student's learning ability for up to $18 \%$ compared to traditional method. Also, the students were excited about learning and motivated to gain more knowledge during the lessons. Furthermore, the study seems to prove that students are able to retain information effectively and microteaching aids their long term memory. 
Mohammed,G.S., Wakil,K. \& Nawroly,S.S. (2018). The effectiveness of microlearning to improve students' learning ability. International Journal of Educational Research Review,3(3),32-38.

In the future, we intend to embed smartphones and tablets in Microlearning. Also, we like to know the impact of using Microlearning in small towns and villages. Moreover, we would like to see how Microlearning will affect in high schools, universities, other educational and academic institutes.

\section{REFERENCES}

Baumgartner, P. (2013). Educational dimensions of microlearning-towards a taxonomy for microlearning. Designing Microlearning Experiences.

Cates, S., Barron, D., \& Ruddiman, P. (2017). MobiLearn go: mobile microlearning as an active, location-aware game. Paper presented at the Proceedings of the 19th International Conference on Human-Computer Interaction with Mobile Devices and Services.

Edge, D., Fitchett, S., Whitney, M., \& Landay, J. (2012). MemReflex: adaptive flashcards for mobile microlearning. Paper presented at the Proceedings of the 14th international conference on Human-computer interaction with mobile devices and services.

Freeman, L. E. (2016). Microlearning, a video series: a sequence of videos exploring the definition, affordances, and history of microlearning.

Gassler, G., Hug, T., \& Glahn, C. (2004). Integrated Micro Learning-An outline of the basic method and first results. Interactive Computer Aided Learning, 4, 1-7.

Gutierrez, K. (2015). Numbers Don't Lie: Why Bite-Sized Learning is Better for Your Learners (and You too).

Hug, T., \& Friesen, N. (2007). Outline of a microlearning agenda. Didactics of Microlearning. Concepts, Discourses and Examples, 15-31.

Ozdaml, F., Kocakoyun, S., Sahin, T., \& Akdag, S. (2016). Statistical reasoning of impact of infographics on education. Procedia Computer Science, 102, 370-377.

Renard, L. (2017). Microlearning, a new way of teaching without losing attention.

Wakil, K., Muhamad, D., Sardar, K., \& Jalal, S. (2017). The Impact of Teaching ICT for Developing Education Systems. International Journal of Advanced Research (IJAR), 5(7), 873-879. doi:10.21474/IJAR01/4793

Wakil, K., Omer, S., \& Omer, B. (2017). Impact of Computer Games on Students GPA. European Journal of Education Studies. doi:10.5281/zenodo.827400

Wakil, K., Qaisar, N., \& Mohammed, C. (2017). ENRICHING CLASSROOMS WITH TECHNOLOGY IN THE BASIC SCHOOLS. European Journal of Open Education and E-learning Studies. doi:10.5281/zenodo.841925 